\title{
Paradoxical Procoagulant Effect of Early Doses of Warfarin: Possible Role of Non-Vitamin K Oral Anticoagulant in Patients with Atrial Fibrillation- Related Stroke
}

\author{
Yesel Kim, Oh Young Bang \\ Department of Neurology, Samsung Medical Center, Sungkyunkwan University, Seoul, Korea
}

Dear Sir:

Patients with atrial fibrillation $(\mathrm{AF})$ seem to be at an increased risk for ischemic stroke during the initial stages of warfarin prophylaxis. A recent case-control study showed that warfarin was associated with a $71 \%$ increased risk of stroke in the first 30 days of use, whereas decreased risk was observed after 30 days. ${ }^{1}$ Moreover, in the Rivaroxaban Once Daily Oral Direct Factor Xa Inhibition Compared With Vitamin K Antagonism for Prevention of Stroke and Embolism Trial in Atrial Fibrillation (ROCKET-AF), stroke recurrence was higher in patients transitioning from rivaroxaban to warfarin. ${ }^{2}$ Two possible mechanisms for the increased stroke rates in patients treated with warfarin de novo include a long delay until therapeutic INR values are reached (only $6 \%$ of them involved bridging therapy) and a possible prothrombotic activity of warfarin at treatment initiation.

Herein, we report a case of recurrent stroke and enlargement of thrombus in the left atrial appendage (LAA) during the initial stage of warfarin therapy after stroke.

A 55-year-old man with known AF presented to the emergency room with symptoms of left-sided weakness and neglect. The patient was diagnosed with paroxysmal AF. He was taking aspirin, clopidogrel, and medications for hypertension and hyperlipidemia. His initial NIHSS score was 14 (facial palsy 1, gaze 2, visual 2, arm 3, leg 3, dysarthria 1 , and extinction 2). Non-contrast $\mathrm{CT}$ scan and CT angiography showed an occlusion of the right M1 branch. Immediately after the CT scan, he was started on 0.9 $\mathrm{mg} / \mathrm{kg}$ intravenous $\mathrm{tPA}$ regimen, and all his symptoms improved within 5 hours. MR angiography showed complete recanalization of the occluded segment. On post-infarct day 1, coronary CT angiography was performed, which showed a $1.5 \mathrm{~cm}(1.57 \mathrm{~mL})$ thrombus residing in the LAA (Figure 1). At 24 hours after the administration of intravenous $\mathrm{PA}$, it was decided that he would benefit from a warfarin slow-start regimen ( $3 \mathrm{mg}$ daily in this case) for stroke prevention because of the bleeding risk. On the 8th day after the initiation of anticoagulation, his INR reached 1.7 , but there was a recurrence of left-sided weakness. The patient was brought into the angiography suite for endovascular therapy. Successful recanalization was achieved using Solitaire stent retrieval. The removed stent had a dark red-colored thrombus that was $20 \mathrm{~mm}$ in size. He recovered completely 3 hours after the procedure ended. The follow-up CCTA showed increase in thrombus size in the LAA, measured to be $2.7 \mathrm{~cm}(2.88 \mathrm{~mL})$. For surveillance, we checked the coagulating profile; the protein $\mathrm{C}$ level was 30\% (normal range, 80\%-160\%), and the protein S level was $37 \%$ (normal range, 52\%-136\%) during early warfarin therapy. Other laboratory results were within normal ranges.

This case illustrates the importance of considering the paradoxical procoagulant effect of warfarin as a possible complication of unopposed warfarin therapy. The paradoxical procoagulant effect of warfarin observed in the early days of the treatment is biologically plausible. While warfarin blocks the activation of clotting factors II, VII, IX, and X, it also deactivates protein C and protein $\mathrm{S}$, two endogenous anticoagulants. ${ }^{3}$ Since protein $\mathrm{C}$ 


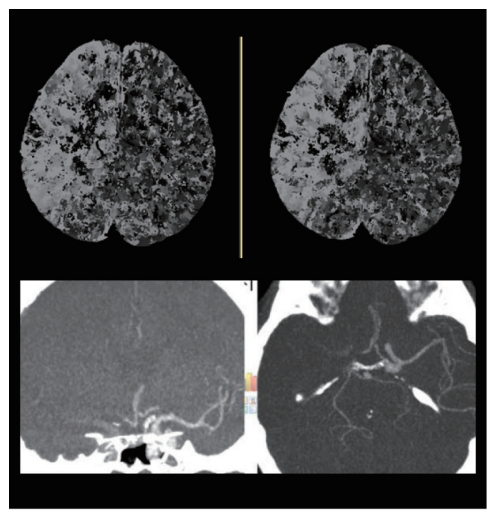

Baseline perfusion CT NIHSS 14

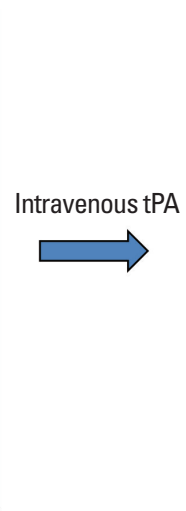

HOD 1

NIHSS 0

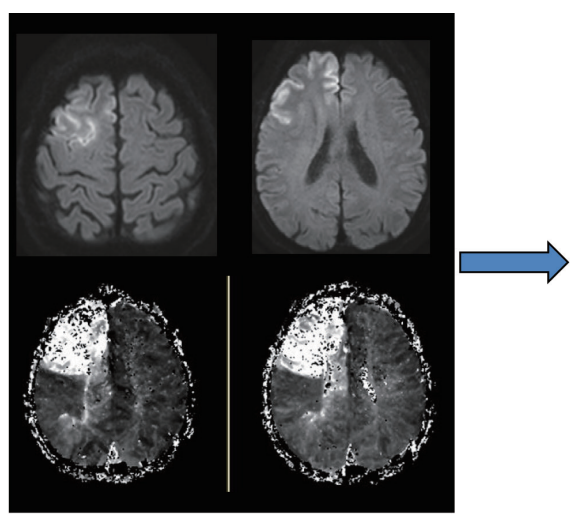

HOD 7: Recur at INR 1.7 $\mathrm{NIHSSO} \rightarrow 8$

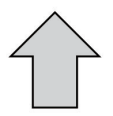

F/U CCTA after warfarin

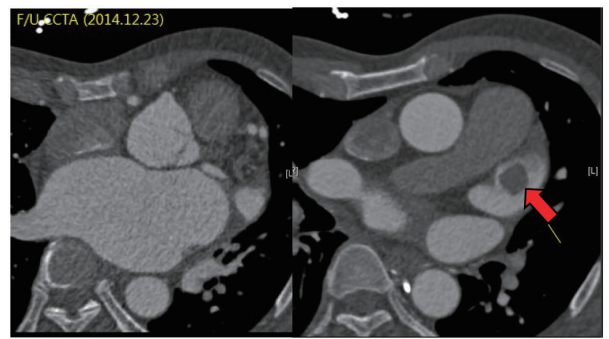

Thrombus volume: $2.88 \mathrm{~mL}$
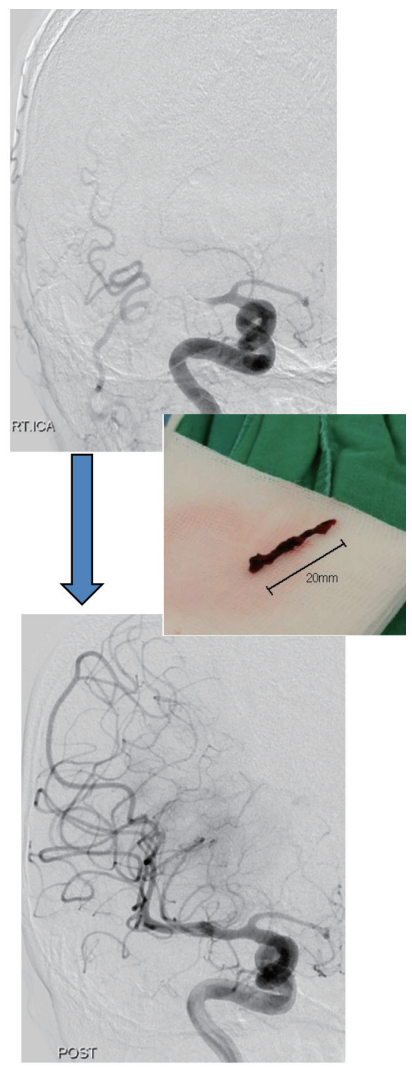

Successful recanalization (TICI 3) with thrombectomy NIHSS 3

Figure 1. Baseline brain perfusion CT and MRI findings at stroke recurrence (upper lane). Serial coronary CT angiographic findings (lower lane).

has a short half-life ( 8 hours) and warfarin initially decreases protein $\mathrm{C}$ levels faster than the coagulation factors, it can paradoxically increase the coagulation tendency when treatment is first begun, leading to massive thrombosis with skin necrosis and gangrene of limbs. ${ }^{4}$ Supporting this hypothesis, the present case showed the thrombotic events observed in the first 7 days of use, which is also concordant with the time of onset of warfarin-induced skin necrosis; the levels of protein $\mathrm{C}$ and $\mathrm{S}$ were decreased at the time of the thrombotic event. ${ }^{5}$ On the contrary, heparin or non-vitamin $\mathrm{K}$ oral antagonists block factors $\mathrm{Xa}$ and IIa and do not deactivate protein $\mathrm{C}$ and protein $\mathrm{S}$ (Figure 2). Thus, bridging therapy with heparin can be considered when initiating warfarin therapy. However, Dr. Hallevi and colleagues compared the adverse effects of anticoagulation with warfarin vs. bridging therapy in patients with cardioembolic stroke and showed that bridging with either heparin or low molecular weight heparin increased the risk for serious bleeding. ${ }^{6}$

Embolization of the clot from the left atrium or LAA is the main cause of ischemic stroke in patients with AF. Thrombus in the LAA is reportedly observed frequently in patients with AF, especially in those with stroke or systemic embolism. In the

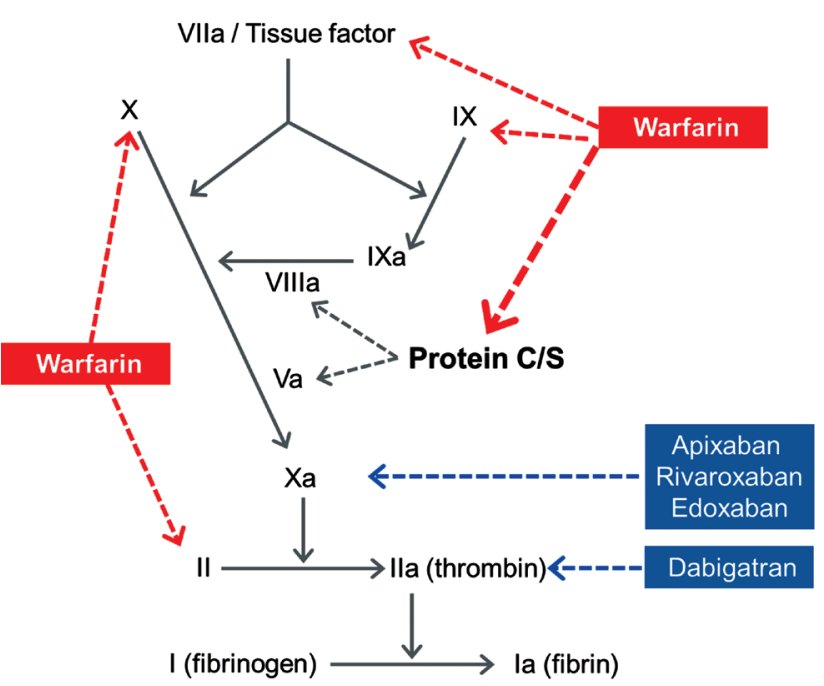

Figure 2. Oral anticoagulants-site of action in the coagulation system. Modified from Weitz et al. ${ }^{7}$

present case, the LAA thrombus was increased in the early days of warfarin treatment, as measured by serial CCTA. A high index of suspicion may guide start heparin or non-vitamin K oral antagonists before the process of adverse procoagulation begins. 
This case suggests performing serial echocardiographic or imaging studies to monitor thrombus size in patients with low protein $\mathrm{C}$ and $\mathrm{S}$ levels during the initial stages of warfarin therapy.

Lastly, our data indicate the possible role of non-vitamin $\mathrm{K}$ oral anticoagulants in patients with high-risk of recurrence, such as those with AF-related stroke. The Rivaroxaban Versus Warfarin in Acute Ischemic Stroke With Atrial Fibrillation (TripleAXEL) (ClinicalTrials.gov Identifier: NCT02042534) study, which examines whether early initiation (within 5 days from stroke onset) of rivaroxaban as compared to conventional warfarin would reduce intracranial bleeding, recurrent embolic stroke, and hospital stay in patients with acute ischemic stroke due to $\mathrm{AF}$, is ongoing.

\section{References}

1. Azoulay L, Dell'Aniello S, Simon TA, Renoux C, Suissa S. Initiation of warfarin in patients with atrial fibrillation: early effects on ischaemic strokes. Eur Heart J 2014;35:1881-1887.

2. Patel MR, Mahaffey KW, Garg J, Pan G, Singer DE, Hacke W, et al. Rivaroxaban versus warfarin in nonvalvular atrial fibrillation. N Engl J Med 2011;365:883-891.

3. Freedman MD. Oral anticoagulants: pharmacodynamics, clini- cal indications and adverse effects. J Clin Pharmacol 1992;32: 196-209.

4. Chan YC, Valenti D, Mansfield AO, Stansby G. Warfarin induced skin necrosis. Br J Surg 2000;87:266-272.

5. Binymin KA, Nasher M, Patel D. Warfarin-induced deep vein thrombosis. Int Med Case Rep J 2014;7:123-125.

6. Hallevi H, Albright KC, Martin-Schild S, Barreto AD, Savitz SI, Escobar MA, et al. Anticoagulation after cardioembolic stroke: to bridge or not to bridge? Arch Neurol 2008;65:11691173.

7. Weitz JI, Bates SM. New anticoagulants. J Thromb Haemost 2005;3:1843-1853.

Correspondence: Oh Young Bang

Department of Neurology, Samsung Medical Center, Sungkyunkwan University, 81 Irwon-ro, Gangnam-gu, Seoul 135-710, Korea

Tel: +82-2-3410-3599, Fax: +82-2-3410-0052

E-mail: neuroboy50@naver.com

Received: January 15, 2015

Revised: February 8, 2015

Accepted: February 16, 2015

The authors have no financial conflicts of interest. 